\title{
"When I steal, it is for the benefit of me and you": Is collectivism engendering corruption in Uganda?
}

\author{
Paul Bukuluki \\ School of Social Sciences, College of Humanities and Social Sciences, \\ Makerere University, Kampala, Uganda \\ Tel: +256 772462100 \\ E-mail address: pbukuluki@gmail.com
}

\begin{abstract}
This paper examines the beliefs and practices that collectivism engenders in Uganda and how they may influence the principal-agent relationships present in the situation of "corruption". Within some specific contexts of collectivism, vices that may qualify to be corruption may be interpreted otherwise as long as they are perceived not only serve only individual but also group or community goals. The paper shows that in some societies in Uganda, corruption or even theft can be acceptable as long as it is perceived to bring benefits to the family, kinship or community. The paper argues that the drivers and manifestations of corruption in Uganda cannot be understood without reference to beliefs and practices engendered by collectivism. It provides examples that show that in quite many collectivistic cultures, acceptance or rejection of corruption depends on the contextual interpretations of the act and the perception and meaning attached to the party to whom the act has been committed. In some cases, especially where the state has either lost or has never gained legitimacy among some sections of the population; stealing state funds may be interpreted as being "smart" rather than immoral. This tendency towards conceptualizing 'corruption' as something that takes place only when the individual does not share his loot with others but enjoys its benefits alone contributes to making individuals shun the individual responsibility for their corrupt actions and complicates the moral issues related to corruption in the context of collectivism. It could be that the level of individuals' sense of responsibility for their actions in collectivistic environments is lower thus making interventions that solely focus on individual retribution less effective in combating corruption.
\end{abstract}

Keywords: Corruption; culture; collectivism; state; public servants; elected officials; Uganda

\section{INTRODUCTION}

Corruption has been conceptualized variously by scholars from different academic disciplines. Economic theorists for example analyse corruption from a formal institutional point of view. They focus largely on the interactions between public servants and private citizens with a view of maximizing their own expected incomes or profits on one hand, and the institutions designed to deter public officials from abusing their positions. The main assumption is that "when the private returns to corruption are higher, due to weak institutions, the likelihood or consequences of detection are limited and individuals are more likely to act corruptly". Corruption, broadly defined as the abuse of public office for private gain by the World- Bank, 
has been acknowledged as a universal problem (Mishra 2005, 349; Desta, 2004, 5). Whether petty or grand or any other type, corruption has adverse consequences (Gupta et al. 2000, 3; Klitgaard, 1998: 3). For example, corruption can drive up the price and lower the level of government output and services (Shleifer and Vishny, 1993), including the provision and financing of health care and education services in many countries. Furthermore, corruption can reduce investment in human capital (Ehrlich and Lui, 1999). Moreover, corruption can also reduce government revenue (Shleifer and Vishny, 1993; Hindriks, Keen and Muthoo, 1999) which in turn can lower the quality of publicly provided services Gupta et al. (2000, 3). As a result some individuals may be discourage from using these services and reduces their willingness to pay for them (through tax evasion), which shrinks the tax base and diminishes the government ability to provide quality public services.

A review of literature reveals that corruption has been conceptualized to manifest itself through many characteristics including: deliberate subordination of public interest to personal ones; tendency of secrecy of execution; consists of situations of mutual obligations and benefits in monetary and other forms; interaction in a reciprocal framework between those who require certain decisions and those who can influence such decisions; processes of covering up unlawful act under a cloak of lawful justification; contradictory dual functions: correct official functions and incorrect corrupt ones; use the same machinery, with which legitimate social functions are performed to engage in unethical behaviour, which negate public interest (Medard, 2003; Egbue 2006; Blundo, 2006).

\section{Brief description of corruption in Uganda}

The Transparency International 2010 report ranks Uganda as the 127th most corrupt country in the world with a corruption perception index of 2.5. Uganda is ranked in the $20^{\text {th }}$ percentile in the control of corruption. According to the National Service Delivery Survey (2008) in Uganda, there was no action taken on $40 \%$ of cases involving abuse of funds in the health sector. As is the case in the health sector, $35 \%, 23.1 \%$ and $33.8 \%$ of the cases involving misuse of funds in primary education, sub-counties and local councils respectively went unpunished (National Service Delivery Survey 2008).

These data provide useful clues on why there is often a chronic lack of or simply poor services at most government points of services. Instead of subsiding, corruption seems to be growing as evidenced by the Global Fund and GAVI scandal where money for HIV/AIDS prevention and treatment, prevention of malaria and immunisation of children among others was abused. Noteworthy, due to corruption in the health sector, for the past six years, the country has not fully accessed resources from the Global fund for TB, HIV/AIDS and Malaria. Consequently, Uganda has had limited resources and thus unable to procure ARVs and undertake timely community outreach and behaviour change communication interventions (Mugisha et al., 2010). Between 2012 and 2013, Uganda has witnessed serious corruption scandals. For example, a forensic audit by Auditor General Office revealed that more than Shs60 billion Uganda Shillings (about 24.5 Million United States Dollars) meant for the Peace, Recovery and Development Programme (PRDP) for Post conflict Northern Uganda was misappropriated by the Office of the Prime Minister (OPM). As a result of this scandal, Britain, Denmark, Ireland and Norway had already suspended aid to the office of the prime minister following claims that staff funnelled $10 \mathrm{~m}$ euros $(\$ 12.7 \mathrm{~m})$ from an aid programme into private accounts (Aljazeera, 2012). 


\section{Conceptualizing Collectivism and corruption}

It has been aptly stated that "corruption in all its myriad forms arises at the intersection between culture, the market and the state" (Rose-Ackerman, 1999: 91). The drivers and manifestations of corruption in Uganda cannot be understood without reference to cultural beliefs and practices engendered that mediate or guide the interactions between different actors in the process of engaging in corruption. Cultural anthropologists tend to argue that these economic models of analysing corruption leave many questions unanswered. They argue that in order to broaden our understanding of the dynamics of corruption and its manifestations in various contexts, we need to "consider the possible role of informal behavioural rules, social norms and social preferences".

This points to the need to take into account the role culture might play in determining the meaning and levels of corruption in specific contexts (Seleim \& Bontis, 2009). The key assumption is that corruption is a social construction and since culture is at the centre of our very existence, it should be problematised in studies and interventions against corruption. Others have argued that "between man and nature hung the veil of culture and he could see nothing save through this medium...meanings and values that lay beyond senses" (White 1940). Given that culture is the medium through which people perceive, understand and interpret things around them (Helman, 2007), we our understanding of corruption would be quite superficial if culture is not problematised. However, these cultural constructions and meanings are not static; they keep changing i.e. they are uncertain and unstable. As James Peacock ${ }^{1}$ argues," human life should be viewed as a whole configuration interwoven of many forces and aspects, all organized by culture (Peacock 2001, 1).

In this paper, I argue that the drivers and manifestations of corruption in Sub-Saharan Africa (SSA) states like Uganda cannot be understood without reference to the socio-cultural context of collectivism. Within specific contexts of collectivism, actions that qualify to be corruption (i.e., abuse of power for private gain) may be acceptable if the private gain is shared with those in one's community.

In many collectivist cultures (Hofstede, 1991; Ikwenobe, 2006), acceptance or rejection of corruption depends on the contextual interpretations of the act and the perception and meaning attached to the act. In collectivism, an individual is obligated to contribute to the community, not only because it is expected of him or her but because the "community is him or her" (Verhoef and Micheal 1997, p. 396 cited in Ikwenobe, 2006 ; also see Hofstede, 1991). The concept of a person in the African collectivist world-view is "first and most importantly that of the community...this means not that the individual is selfless, but that the self is the community" (Verhoef and Micheal 1997, 396 cited in Ikwenobe, 2006). Hofstede (1991, 51) observes that "collectivism... pertains to societies in which people from birth onwards are integrated into strong, cohesive groups which throughout people's lifetime continue to protect them in exchange for unquestioning loyalty".

Two important aspects of collectivism--the suppression of the self in the interest of the community or "the idea that the identity of an individual is not separable from the socio-cultural environment" (Ikwenobe 2006, 53) and the notion of "we are" as a basis for defining identity instead of "I am. In Collectivism, the cultural ideal is "I am because you are" (Tschudi 2006). This is an important inspiration that is in some contexts (e.g. South Africa) is linked to the African concept ubuntu that was popularised by Bishop Tutu (1999) in advocating and executing the work under Truth and Reconciliation Commission (TRC). Tutu prefers to express 
the ubuntu using the metaphor "my humanity is intrinsically related to that of other persons". He presents ubuntu as an African alternative to the Cartesian "I think, therefore I am" versus "I am human because I belong".

Tutu tells us that ubuntu can be used to describe a personal quality: A person with ubuntu is open and accessible for others, primed with a certainty deriving from the experience of belonging to a larger unity. Thus collectivism tends to espouse the demands or aspirations of the community to be superior over and above those of the individual. In this context, man is viewed as an entity that is not necessary an end to itself but rather a tool to serve the ends of others. In this way, collectivism seems to ignore the agency of individuals which is used to as a resource to maneuver structures and norms in order to achieve their goals. This notion of collectivism and how it affects individual responsibility for actions (Cullen, Johnson, and Parboteeah 2007; Mazar and Aggarwal 2011) such as corruption has not been effectively explored (Blundo, 2006).

\section{METHODOLOGY}

\section{1. Design}

This paper is based on a study which employed an exploratory and descriptive a qualitative study design because it is a method of choice to study meaning(s) (Hardon et al., 2001) and I wanted to study the meaning of corruption in the context of collectivism. In addition, this being a cultural study we employed qualitative methods because qualitative research is suitable for delving into deep questions of subjective experience (Denzin and Lincoln, 2000).

The area of study was Kampala District, which is located in the central region of Uganda. It is the capital city and largely has urban characteristics with many slum settlements. About 60 $\%$ of the population living in Kampala are Baganda and belong to the Bantu tribes.

The city has a population of about 2.5 million people (Uganda Bureau of Statistics, 2010). It hosts all the government ministries and its the headquarter of most projects and programs that have relatively big budgets. It is also the epi-centre of business ranging from service industries, agro-processing, construction and big markets (Uganda Bureau of Statistics, 2010).

\section{2. Sampling and Participants}

Study participants were purposive selected because they needed to have the relevant characteristics, experiences and knowledge to share about the research questions (Hardon et al., 2001). Key informants were informants were male and female community members who were perceived to have the relevant characteristics as well as experiences to share in relation to the key research issues.

The key informants were largely drawn from Local council executive members, civil servants, members of Parliament, researchers and academicians especially from the Social Sciences and Humanities, Makerere University.

These were because they were perceived to have information and experiences to share with us in relation to the key research issues.

\section{3. Data collection}

The main methods of data collection were key informant interviews (KIs). Key informant interviews were employed because they allow collection of data on new areas of study (Bloar 
and Wood, 2006). Key informant interviews were also engaged to generate expert views (Hardon et al., 2001) on issues corruption and collectivism. KI interview was conducted in English because the target group could speak English fluently.

\section{3. 1. Data Analysis}

Interviews were recorded and transcribed. The approach used in data analysis was thematic and content thematic analysis (Gilbert, 2008). Data collected from key informant interviews were coded to develop category systems. This was followed by creating subcategories from each of these main categories that were developed (Gilbert, 2008).

\section{3. 2. Ethics}

Ethical approval was sought and given by the Uganda National Council for Science and Technology review board before conducting the study. Informed consent was sought from all the study informants before their participation in the study. Study participants were informed about the purpose of the study, assured voluntary participation and confidentiality.

\section{STUDY FINDINGS AND DISCUSSION}

\section{The meaning and perception of corruption}

The study found that corruption was decribed using many different terms in various alnguages but also various contexts in the same language. It was common to disguise it by using terms that make it less stigmatizing and difficult to define as theft, extortion, or morally unacceptable. One can argue that this is part of the process of normalising practices related to corruption. The terms used to disguise or describe corruption practices normalize corruption and vary from one area to the other and from person to person depending on the context of the transaction. These terms were however, largely linked to the conception of corruption inrespect to informal payments especially in the context of seeking services from the public sector. The terms commonly used across most areas in demanding for informal payments include: Kitu Kidogo (Swahili word implying give something), Chai (tea), lunch, air time, and transport. Given that our study participants were drawn from across many languages, many used terms in the local language and then gave their English equivalents. Among the Acholi, Alur and Langi in Northern Uganda the terms Piny Moko (give something), kilongo, lep picu, and Lak Kalam (refill my ink) may be used while the Japadhola (Luo) in Tororo district use piny Moro. In the central region (Buganda) terms such as genda e'kasawo (literally meaning get me some money), ba'muyiya (be creative and do something), yogera olulimi lwebatergera (meaning speak the language that is 'understandable'. In this context, the speaking the language refers to giving cash before narrating one's health problem) and vayo gyoli (implying come to my level and get me some money from your bag or wallet) and Kyalako e'Bukoma Nsimbi (literally meaning give money). Bukoma Nsimbi is a village in Buganda, which if literally translated means where money stops and is often cited in reference unofficial payments. As service users line up, mentioning Bukoma Nsimbi signals to them that they will need to pay some money to access services. Others use terms such as scratch my back, oil my knees, and be a man or woman of the people in reference to unofficial payments.

In alerting their colleagues that a service user has no money, service providers in central region districts were said to use the term Talina Musayi literally meaning that he/she has a low 
blood, which in their circles means the person has no money) (see Transparency International, Uganda 2011).

The basic and simplest meaning of corruption was that, corruption is the abuse of office for personal/selfish reasons as an individual. The perception of corruption however, became complex when it was perceived not to just benefit the person (personal or private gain) but the benefits were perceived to be shared by others including extended family, lineage and even community.

Normally in civil service your superior/supervisor introduces the corrupt idea by sending you to bring him or her money or expecting money from you as they deploy you common in traffic police where officers who are deployed are expected to report to their superiors with money from the field. Your colleagues too entice you into corruption. Your family and relatives also urge you to steal like others and also immerse wealth like other corrupt officials (Retired Commissioner in the Public Service)

This study participant brings in the perceptive of the family and your peers encouraging you to steal not just for your sake but also for their benefit. In this context, we also need to appreciate that in Africa and Uganda in particular, the concept of family is that of an extended family. In this case, the stealing is perceived by some not only for personal again but for "our gain" as friends, family or lineage (also see Laurent 2000, 234; Blundo 2006, 33). This may bring into question the meaning of person or person-hood in different cultures. For example, in most of Sub-Saharan Africa, the person is not an individual but he sees himself as an individual in the context of a community. In other words the self is not visible like in societies in the "West". The individual is not separable and clearly separated from the extended family and community. Thus in some cases, like the respondent has noted corruption is a collective racket instigated and planned by the family and peers.

This perception of corruption only partially concurs with the Transparency International definition of corruption which conceptualizes corruption as "the abuse of entrusted power for private gain which eventually hurts everyone who depends on the integrity of people in a position of authority" (Transparency International UK, 2011:1). In the context of collectivism, where the family and community may to a certain extent for context specific reasons be encouraging someone to engage in corruption for the benefit of the family, lineage or community, this definition may be inadequate.

The study found that corruption is perceived differently by various study participants. Some participants perceived corruption to be linked to poverty dynamics but in other cases, corruption was related to the expectations people have of public officials and politicians. It was also linked to how people perceive government and the state - citizen social contract relationship. In the perception of some of our study participants, public officials are expected to be rich even when they are under paid. The people are not interested where one gets the money as long they have it.

The public glorifies the corrupt and look down upon the poor but honest and ethical civil servants forcing many to join corruption to avoid being condemned by the society if they don't get rich (Retired Commissioner, Public Service).

There was a perception by some study participants that government is impersonal and abstract. It is not frequently uncommon for people not to perceive state resources as their public resources. This may also point to issues related to the absence or legitimacy of the state to the 
people in a given community or region (also see Medard, 2002). The perception that government is abstract would mean that "when you steal from governments you are stealing from nobody".

Because government is impersonal, you cannot identify with it. Our minds are not tuned to institutions of government, it is absent. If you steal from something abstract, you are not touched or cannot be felt...Community sanctions about local actions of stealing are there and practiced, but they do not know how to react when one steals from government (Senior Lecturer, Department of Peace and Religious Studies)

To some study participants, corruption was also perceived to be an alien concept and linked to the "West". They found it difficult to understood it in an "African setting" like Uganda. One of the respondents argued that:

The conceptualization of corruption is from the Western angle - our society expressions are to do with acquisition or theft. Pastoralists - when they raid cattle they look at it as acquisition while others look at it as theft. We need to understand what corruption is in the African setting. The current conceptualization is too alien - it is like defining poverty in form of dollars in a non-cash economy. (Senior Lecturer 1, Department of Political Science)

If we relate the quote about government being personal and abstract, making it complex for people to perceive someone stealing from government as stealing from any one or even stealing from them - because government would be their trustee and the above quote which perceives corruption as alien then this may call for contextualization of corruption in settings where the state is perceived as not representing the interests of the community. Thus in contexts where public resources are not perceived by the population as their resources or where public resources are perceived by the communities as "actually private resources that are used by those in charge of the state as more or less their own private resources", the meaning of public resources becomes more complicated.

This is similar to what Medard calls a "neo-patrimonial of regulation found in authoritarian regimes which ensures relative political stability as long as corruption reproduces itself in situations characterized by an admittedly precarious balance between extraction and redistribution" (Blundo, 2006, 51; also see Medard, 2002, 2003).

State failure to provide basic social services as a driver of corruption has led to perception of elected representatives as providers rather than facilitators of access to services through enabling policies and legislation.

The study findings suggest that state failure to provide basic social services or to full fill the state citizen contract has complicated the relationship between people and their elected representatives. Instead of people looking up-to-the state for provision of social services, they seem to actually look-up-to individual elected representatives for provision of these services. For example, Members of parliament tended to argue that corruption is perpetuated by state failure to provide basic services to the population. It was noted that because of this failure, the electorate look up to their elected representatives to provide basic services. Those who fail to do so would be regarded as non performers and would therefore be susceptible to losing their seats. Thus the conceptualization by the electorate of the role of a Member of Parliament as provider could be among the factors making members of parliament and other elected leaders to engage in corruption. This could also explain why as long as a Member of Parliament or a 
Cabinet Minister steals public funds but is giving hand outs to his or her electorate, he is considered a "hero not a thief". The electorate perceives leaders as providers rather than facilitators of access to services. During the course of the study, it was observed that elected councilors are under a lot of stress to provide things that are not constitutionally under their mandate to offer to the electorate. Although the roles of elected representatives ranging from Members of Parliament, District elected representatives at local government levels are clearly stipulated in the Local Government Act and the Constitution, the attitudes of both the electorate and the elected representatives seem to be at variance with these formal roles.

It is common to find elected representatives making promises that are far-fetched from their mandate and for which they are not vote controllers in terms of resource allocation. Thus the expectations of the electorate place a lot of pressure on the elected leaders. This sometimes forces leaders to engage in corruption because they have to look for funds by all means to try and fulfill their promises to the electorate. The elected representatives and electorate are therefore trapped into an informal political discourse that has implications for the ability of elected representatives to perform their formal responsibilities as well as culturally contextualized responsibilities that appeal to their electorate. The dilemma for the councilors is that if the culturally underpinned expectations of the voters are not met, they may endanger the chances of elected representatives being re-elected. This may be partly driven by the reality that a proportion of voters may not know the roles and responsibilities of the elected councilors (also see Neema and Bukuluki, 2011).

Government is not providing the basic needs to the societies. People get little money and they use their offices to compensate themselves. When you are holding a position and you do not help your people then they take you not to be a performer. (Key informant interview, Member of Parliament from one of Counties in West Nile Subregion)

Furthermore, the study findings established that society expects elected officials to fulfill their promises made during campaign for political offices. During campaigns aspirants promise to construct roads and to improve service delivery in their constituency. These promises are outside the mandate of elected leaders.

The other societal expectation is that an elected person should provide for society. This puts them in jeopardy. It is not the mandate of an elected official to provide. He is supposed to articulate the concerns of society in the public space. But to say that he provides for weddings, bridges, burials, this means that he has to use his personal resources yet this is not possible to use personal resources to provide to society and simply does not work - some people have overstretched by trying to provide because of society expectations. (Key informant interview with an Associate Professor, Department of Political Science)

Some politicians go for political campaigns and say if you elected me, you will never see any pothole in this road. Promising what they can't do and they are promising what they have no mandate to do. You may find some political leader if he can't do it but he has influence and so he can influence and they begin diverting a planned activity somewhere to what fits their political interests. If this marrum road was supposed to be graded, somebody influences the other politician to divert the planned road to be graded to another road. Others may want to use their resources which they don't have them then they end up stealing. So these politicians sometimes what they promised during the elections pushes them to do what they may not have done because they promise heaven 
on earth. (Key informant interview with Board Member, Transparency International Uganda)

These expectations make public officials and elected officials strive to meet them amidst scarce financial resources. This lays traps for these officials to engage in corruption related practices. It was noted that elected officials are expected by society to provide and support in every aspect to their electorate and constituency. Some of the key areas where elected officials are required to provide and give support include school fees, burial expenses, funeral rites, worship centers etc.

Elected officials are expected to provide and support in every aspect to their electorate and constituency by giving them jobs, financial contribution for activities like burial expense, weddings, last funeral rites, school fees, award of contracts etc to his relatives, tribe mates, clan mates which fuels tribal patronage and have pressure elected public officials to embezzle public resources (Retired Commissioner Public Service).

Study participants observed that when public and elected officials fails to address the expectation of society, they are accused of being self centered thus in order to meet societal expectations both public and elected officials are pressured into engaging in corruption.

Society expects an elected official or public official to be able to solve their personal problems including paying school fees for children, medical bills etc. And when they do not meet these expectations, they are accused of being self centered. These pressure force public officials to engage in acts of corruption (Chief of Party, for a large NGO in Uganda).

Furthermore, the study findings established that political offices have been commercialized. The commercialization is linked to how the politicians and local leaders perceive their roles. The community because of its collectivism tendencies as well as state failure to provide services perceives elected representatives as chiefs. Similarly, elected representatives seem to have accepted this position even when it is at variance with their constitutional roles. The notion of what is commonly called individual merit that started in the early 1990s when the National Resistance Movement came to power was built on the notion that you need to show what you have done for your community to convince them that you are the best candidate. This meritocracy was not necessarily linked to representation of people's ideas and needs in Parliament but linked in many cases to the material things and infrastructural projects like schools, roads, water sources that you have put in place for your community. The process of getting into public offices is therefore expensive. The people vying for political offices buy votes and make huge promises in order to be elected. Those who get elected may become corrupt in order to recover their expenses. As elections draws near, incumbent politicians steal money in preparation for the elections as they have to buy voters.

Corruption starts with elected officials, the people vying for political offices make wild promises during the campaigns. They are unprincipled, they make wild promises just premised to winning an election and they tell what the electorate want to hear even when they know its outside their mandate and not able to deliver on their promises and without telling them lies one may not win election. On the other hand, they buy votes, and when they get into offices they get corrupted in order to recoup their initial investment and enrich themselves and it becomes a vicious circle. (Retired Commissioner, Public Service) 
Another study participant further argued that the society looks at the positions of elected leaders as jobs rather than service to society and that the process of acquiring these positions is perceived as investment for enriching elected officials.

Expectation of society of the elected leader; They look at their positions as jobs rather than service to society and the process of acquiring these position is perceived as investment for self enrichment. The people on the other hand look at the election process as a way of getting something from the aspiring politician. The electorate has to be paid or bribed to vote for a candidate and expect to continue being bribed. As such the candidate who is able to spend more money will have the most number of votes. In doing so, some candidates will have their assets auctioned and when they get elected, they will have no choice but to engage in acts of corruption to recoup what they spent! Most voters tend to vote money not issues (Senior Official, Ministry of Finance, Planning and Economic Development)

\section{1. Collectivism, reciprocity and corruption}

The study established several meanings of corruption in the context of collectivism. It revealed that some cultural practices like "envuujo in kiganda" culture meaning "giving gifts to people with power like chiefs, land lords" have become building blocks for corruption. In addition, proverbs like "akuwa obwami aba akuwadde kulya" which literally means, "one who makes you a chief or who gives you a position of substance or power in society has given you a platform to eat" seems to indirectly reinforce practices that could lead those elected into office or promoted to high positions in the Public Service to become corrupt.

Abuse of the notion of reciprocity: reciprocity is central in many African cultures but it can be abused by public officials. The Culture for example, allows acceptance of gifts. Rejection of the gift would be demeaning because reciprocity is considered a natural thing in African culture.

It is common for public official to expect reciprocity after delivering a service to the public, say processed a license, permits, visas etc. There is a tendency of members of the community to reciprocate by giving gifts in form of cash which sometimes become routine and public officials then expect from everybody thus promoting corruption in public service (Associate Professor, Department of Political Science).

\section{Kinship, social ties, networks and vulnerability of public officials to corruption}

Several study participants noted that despite the positive attributes of the extended family such as being there for kinsmen and women during turbulent times, the unending social and material needs of the kinsmen/relatives and demands for reciprocity in the traditional extended families put a lot of pressure on elected officials and public servants.

Civil servants and Politicians have pressure to cater for their basic and strategic needs of their relatives. Several study participants noted that relatives, believe that when one of their own extended family or kinship is well placed in the central or local government establishment; they have to get jobs, money, tenders and many favors. This has made a number of politicians and technocrats in the public service and local government engage in corruption.

The extended family obligations embedded into "African cultures" in many African countries including Uganda demand for reciprocity and unquestionable royalty to your clan and extended family members (Hofstede, 1991; Gyekye, 1996; Ikwenobe, 2006). For example a husband is expected to have money to support his in-laws whenever they have a financial need. In Luganda there is a demeaning proverb for a poor in-law; "Omuko Omwanvu ye ayasa enku 
ku buuko". Literally meaning that; "it is a poor son-in-law who does donkey work at the home of his father in-law". Therefore gender norms around masculinity and an ideal man or son-inlaw makes Public servants and elected leaders susceptible to stealing in order to meet the exepectations of their in-laws.

In addition, peer pressure within people working for central government, Local government and the civil society as well as pressure within the family for civil servants and politicians to leave beyond their means was perceived as a key driver of corruption.

“...unending social needs of our traditional extended families, the drive to compete or outcompete our peers in terms of material wealth beyond what our incomes can ordinarily manage, are some of the factors that push people to engage in illicit acts of wealth acquisition. There are cases where wives have forced husbands to engage corruption to even up with people that are esteemed in society. In fact even in churches, people who give more offertories are treated differently..." (Senior manager, for one of the big Non Government Organisations)

A high expectation from the many dependents associated with extended family was perceived as a driver of corruption. One of the respondents noted that:

"One person with a reasonable income is supporting many others because of extended family thing promoting the "we thing". It comes about because many people cannot earn a living - so many people use collectivism to get to you. We owe our success to others and we pay back to society by helping others. The problem is that we end up in unconventional methods such stealing, embezzling to get resources to support the many dependents. The dependents we support - see nothing wrong with stealing money, the villagers are not concerned about how you get the money as a relative or Member of Parliament as long as you support their needs" (Member of Parliament, for one of the constituencies in Central Region).

Another study participant observed that in the African setting, even the elite find it very difficult to complain or re-think his position on issues of reciprocity and establishing boundaries between the nuclear and extended family. Thus the borders between the nuclear and extended family and the community are porous.

"This concept of communalism is what Africans define themselves to be - clan system, extended family; issue of who are my people, children of your brother are your children and this puts pressure on you, but who cares. You cannot go to your mother and complain that your back is breaking because of the children of your brother or sister. You are supposed to meet the needs and that is it. You cannot complain and you cannot re-think your role. Any attempt to do that will be interpreted as being insensitive - that you have no heart. Therefore Members of Parliament and other public officials are thus forced to be corrupt to address the needs of dependants" (Senior Lecturer, Department of Sociology and Anthropology).

\section{Perception of Ideal Man in society and predisposition to corruption}

The study revealed that the masculinity and gender norms associated with "being a man or ideal man" in society such as Uganda carries with it expectations and responsibilities which may ultimately predispose a man to corruption practices. Society expects a man to have wealth and the society does not mind about the source of the wealth. The Society gratifies the corrupt calling them heroes and ridicules the non-corrupt calling them stupid! A man is expected to have a big house, second home, wife(s), and his children should go to good/expensive schools, 
have a big car. Being a man means that you are a provider. Society expects you to have ability to provide for your immediate family, your parents' family and the family of your wife.

If you are not able to provide for your family - or you are unsuccessful you are not considered a man. Men go over because they pushed to be successful and to succeed. The idea of a man is not just a physical being. "Omushaija or obushaija abweteera". If you are a man you must demonstrate that you are man. You must demonstrate success through harvest, cow decent house, banana plantation and coffee. This drives some men crazy and sometimes corrupt - craving for success by all means. Expectations of society on Person who is responsible and can take care of others. (Associate Professor, Department of Political Science)

It is true that expectations and responsibilities of being a man predispose men to be corrupt because they look at a man as a bread winner. A man is expected to do everything (Member of Parliament, one of the Constituencies, Central Region).

Today if I am made a big person in a big office responsible over huge sums of money. All my friends, my family especially my wife and children and my clansmen will now be looking at me as a source of earning that they can easily come to me for support and I must give that support. Sometimes I may also want to do the same, but in the process I will be overstretching myself to make everybody happy which I can't maintain. So sometimes to be a man you must manage every problem financially yet you can give advice without money and someone gets out of the problem. The moment you fail you overstretch yourself and you think otherwise, you end up making false claims, even failing to account for money, embezzling money because you want to fulfill the demands of your family, relatives and friends. (Board Member, Transparency International Uganda Board)

Using your networks/social ties as an advantage over others not perceived as corruption in some collectivistic settings:

Collectivism and its socialization processes have made some people blind to corruption especially in awarding jobs and contracts. Several study participants argued that if a friend or a relative approaches you for a job when you are in a public servant but he or she has the requisite qualification and you use your power or position to make this person get a job then this is an issue to do with using your networks and does not amount to corruption. It is rather maximizing your social capital to benefit people who are qualified but close to you. Participants argued that where a person approaches you and this person is incompetent and without requisite qualification and you use your power or position to make this friend or relative acquire a job then that would be corruption. This was further explained more precisely by one of the respondents.

A combination of connections and qualifications should be fine, but where people are not qualified but they are employed because of their relatives. If they take undue advantage, then that would be corruption. But if somebody gets through the rigors of recruitment and gets a small push - that should not be corruption. (Associate Professor, Department of Political Science)

\section{Using Social ties to elude Justice for corruption related practices:}

Social ties are used as a tool or shield for protection against prosecution in the formal retributive Courts of Law. This is especially for those with relatives, close friends or connections in government. It was noted by some study participants that if the corrupt official 
is perceived as still politically useful i.e. still capable of mobilizing the electorate for votes, he or she will be protected by those at the helm of the state.

"... it is not uncommon that people in influential public positions bent the rules to favor their in-laws, sisters or clan mates". This thread runs through from the highest to the lowest public office. (Chief of Party, for one of the large NGOs)

Agency vs. collectivism:

Some study participants disagreed with this notion of saying that people are hostage of collectivism and therefore cannot exercise their agency. They noted that politicians and public servants are simply abusing collectivism and using it to steal and amass wealth. These study participants observed that it is debatable if all the funds accruing from corruption related deals/scandals are used to support kinship networks. They argued that engaging in corruption and tolerating those who do it is a matter of attitude rather than being hostage of collectivism. Some public officials irrespective of social ties may reject corruption. The study participant further explained this debate.

When you look at cases of corruption - it is not necessary - net works - it is debatable if the stolen money is used to support kinship networks. It may go more into attitude - whether corrupt or not you can support the network. The network could be an incentive to get involved in corruption but it is an issue of attitude - you can do the responsibility without being corrupt. (Senior Lecturer, Department of Political Science)

\section{2. Useful Cultural resources that can be utilize in the struggle against corruption in the context of collectivism}

There are several useful cultural practices that the study established that can be utilized in the struggle against corruption in a collectivist society like Uganda. Among the useful cultural resources found was cultural norm. The study participants revealed that every tribe in Uganda preaches morality to the young people.

Cultural norms can be used. In every culture of the tribes in Uganda the concept of morality is key, and many traditional proverbs promotes equity, integrity, fairness, responsiveness, participation etc which can be evoked to promote transparency, accountability and integrity. Young people are supposed to be obedient to cultural norms and to elders, thieves are under looked and despised (Retired Commissioner Public Service)

It was further noted that religious teachings are against stealing and exploitation.

Religious values teach Christians to avoid stealing. However, the church can still rise up against corruption. (Senior Official, Uganda National commission for UNESCO)

The study participants argued that societal values even within collectivism are against stealing and thieves. However it also pointed out that social cohesion is no longer strong as it used to be.

Our societal values are against thieves - the community prefers people to help others but not necessarily though stealing. In the traditional African society, the social control mechanisms and norms can be used but we are in a changed society; there is no longer social cohesion. What we need is a political mechanism not social or cultural resources because they have been all eroded. We are living in a different society all together. (Senior Lecturer, Department of Political Science). 
The study revealed that stigmatizing the corrupt and their families is one of the cultural resources that ought to be used to fight corruption.

The Politician who engaged in corruption scandals, are publically stigmatized, their families are stigmatized for example by virtue of mentioning a corrupt minister, there is already social stigma. When you are a child of a corrupt minister in a secondary school and you annoy, another child, the response would be what are you talking when your father is even a thief he stole public money. See the stigma this type of child will go through. If the society decides to be collective against you because of something you are doing, you are finished. (Member of Parliament representing one of the marginalized groups).

The study findings further revealed that societal respect for faithful and trustworthy public officials is another useful cultural resource for the fight against corruption in a collectivist society like Uganda. The study participant argued that society respects those who are faithful and trustworthy and not those who steal public funds.

In our society, people will respect you if you are faithful, if you are trustworthy. Our culture does not support people to steal or to cheat. But this culture is being killed by the very people, the modern youths and the old people. And the youths are also looking at the old people and they are saying if this man went to parliament and he has amassed wealth in four years, if I became minister I also want to look like him. So cultural values are getting lost or eroded because of peer influence. Very few people are now stuck to them yet cultural values would have helped us to safe guard our people from stealing public funds. (Board Member, Transparency International Uganda).

\section{DISCUSSION AND CONCLUDING REMARKS}

This study observed that collectivism especially when viewed in terms of its socialization processes and the demands it puts upon individuals, families and communities may predispose them (public officials, elected leaders) to engage in corruption (also see Laurent, 2000, 234). The study also shows collectivism does not in itself encourage anyone to engage in corruption per say. Individual public servants and politicians are not necessarily taken hostage. They have their own choices that they can make to remain corruption free irrespective of the many drivers in a collectivistic context that may make them vulnerable to corruption (also see Anders 2005, 213). In other words, collectivism cannot be taken as an excuse for engaging in the vice of corruption. There were debates among study participants that seemed to suggest that public servants and elected representatives are taking advantage of communities under the guise or cover of collectivism to engage in corruption related behaviours (also see Anders 2005, 213; Blundo, 2006, 33). Viewed from this perceptive, corruption is an issue of attitude of the political leaders and public servants in their interaction with families and communities. This is similar to the argument by Anders that: "on the contrary, far from being prisoners of social obligations, social actors retain a certain margin of maneuver and use this argument to justify their illicit practices" (Anders, 2005, 213; also see Blundo 2006, 33-35).

State failure to fulfill its citizen-state social contract of providing basic social services comes out quite clearly as a key concern in making elected officials susceptible to use all means possible to do things outside their mandate to provide for the communities. The attitude of the community towards elected leaders continues in many respects to perceive them as 
chiefs/providers rather than representatives in Local Councils or the Parliament. Although this is not an excuse for engaging in corruption, it provides an enabling environment and may give politicians an excuse to abuse "public Resources". As rightly pointed out by Anders, a detailed study of the social life of public workers helps to enhance our understanding of the intricate and complex nature - relationship of both the state and corruption (Anders, 2005, 192) in collectivistic settings.

State legitimacy or state absence in the daily lives of communities and how it relates to the communities perception of the state or government resources is an interesting issue for further research. If the state is not perceived as a trustee for the community but perceived as belonging to the political and military elite in power, it raises the question of what is then the state and whose interests it serves. It also puts the community in some kind of dilemma when it comes to perception of what constitutes public resources. Thus if public resources are actually not perceived by the citizenry as so, then meaning and parameters for measuring corruption as applied in (and by) the "West" may not make sense.

This is more so in the context of collectivism especially in communities where there are failed states or where state legitimacy particularly measured in terms of the state fulfilling its state-citizen social contract is in question. This argument augurs well with the issues raised by Jean Francois Medard while discussing the concept of neo-patrimonialism which "characterizes the contradictory nature of the African states in which processes of bureaucratization co-exist with the patrimonial management of public resources" (Medard, 1990, 27 cited by Blundo, 2006). In essence, although the Constitutions of African states acknowledge the distinction between public and private spheres, this division is not respected or is often ignored in concrete political practices of the "African" leaders (Medard, 2002; Blundo, 2006). Seen from this perspective, I agree with Medard's notion that neo-patrionalism show signs of the failure of the institutionalization of the state in Africa (Medard, 2003; also see Blundo, 2006, 21).

Similarly, our findings are in agreement with Blundo (2006)'s observation that the informalisation tendencies of the bureaucracy that characterize political practices of some African states makes the state both a "shadow and real". "It does not constitute a pale copy or distortion of the Weberain state but represents something radically different" (Blundo 2006, 22). It emerges from the study that gender is one of the central concepts in understanding the dynamics and drivers of corruption in the context of collectivism. It is plausible that the masculinity and gender norms constructed around an ideal man in the "African" context and the expectations that come with them predispose people to engaging in corruption related practices. This may help to explain the masculine face of corruption (also see Dollar et al, 1999; Transparency International 2009).

This study also demonstrates that we should not be blinded to only focus on the drivers of corruption in the context of collectivism (Cullen, Johnson, and Parboteeah 2007) and ignore the cultural resources within collectivism that can be harnessed in the struggle against corruption. There is limited research on cultural resources for fighting corruption yet these are common place in the "African" collectivistic values stemming from culture and religion as well as the entire socialization process (Hofstede, 1991; Gyekye, 1996; Ikwenobe, 2006).

In this paper, I argue that the drivers and manifestations of corruption in Sub-Saharan Africa (SSA) states like Uganda can at best be understood by reference to the socio-cultural context of these societies. As seen from the perspectives of study participants, specific contexts of collectivism, actions that qualify to be corruption may be seen by some community members as acceptable if the private gain is perceived to be actually public because it is going to be shared with those in one's community. If this is seen from the perspective that an individual is obligated to contribute to the community, not only because it is expected of him or her but 
because the "community is him or her" (Verhoef and Micheal 1997, p. 396; also see Hofstede, 1991; Ikwenobe, 2006).

From an academic perspective, it has been noted that few anthropological work problematising the issue of culture, its different levels and its complexity (Helman 2007) has been done on the phenomenon of corruption in Africa. As Giorgio Blundo noted while commenting about "Africanist" Anthropology and corruption;

...Despite being the first academic discipline to have set foot on the African soil, anthropology is the one that has devoted least attention to the subject of corruption there...(Blundo, 2006: 16-17)

I conclude by stating that the issue of culture and context is imperative in aiding understanding of the latent and manifest aspects of corruption, more so in the context of collectivism in Uganda. There is therefore need to problematise culture and context in studying corruption in all its forms (also see Van der Geest 1984).

\section{ACKNOWLEDGEMENTS}

I want to thank Prof, Taryn Vian, Boston University for reviewing my initial abstracts and for providing input to the research instruments. I also want to recognize the work done by my research assistants especially Alex Bagabo, Francis Kato, Robert Lugolobi, Kiwungulo John and Jimmy Obonyo. I am also grateful to all the study participants for generously sharing their views and experiences.

\section{References}

[1] Anders G., Civil Servants in Malawi: Cultural Dualism, Moonlighting and Corruption in the Shadow of Good Governance, Law Faculty Erasmus University Rotterdam, 2005.

[2] Aljazeera, UK suspends Uganda aid over corruption: Allegations of embezzlement in the prime minister's office prompt suspension of development assistance worth $£ 27 \mathrm{~m}$. Source: http://www.aljazeera.com/news/africa/2012/11/20121117155051480786.html accessed on 18 May 2013.

[3] Bloar Micheal, Wood Fiona, Key words in qualitative methods: a vocabulary of research concepts. London: Sage Publications, 2006.

[4] Blundo Giorgio, Corruption in Africa and Social Sciences. In G. Blundo and J-P Olivier de Sardan (eds). Every Day Corruption and the State, Citizens and Public Officials in Africa. London and New York: Zed Books.

[5] Dollar David, et al., Are Women Really the Fairer Sex? Corruption and Women in Government, World Bank Working Paper Series No. 4 (1999).

[6] Desta Yemane Designing Anti-Corruption strategies for Developing Countries: A country study of Eritrea, 2004. Ph. D. Thesis North Carolina State University.

[7] Denzin K. Norman, Lincoln S. Yvonna, Introduction: The discipline and practice of qualitative research. London, UK: Sage Publications, 2000. 
[8] Egbue N. G., J. Soc. Sci. 12(2) (2006) 83-91.

[9] Ehrlich Issac, Francis T. Lui, Journal of Political Economy 107 (1999) 270-93.

[10] Gilbert Nigel, Researching Social Life. Third Edition, London: SAGE Publishers Inc. 2008.

[11] Gupta Sanjeev, Hamid Davood, Erwin Tiongson. "Corruption and the provision of health care and education services" IMF working paper Fiscal Affairs Department, $\mathrm{WP} / 00 / 116,2000$.

[12] Gyekye Kwame, African cultural values: an introduction. Accra: Sankofa Publishing Company, 1996.

[13] Hardon Anita, Applied Health Research Manual: Anthropology of Health and Health Care. Amsterdam: Het Spinhuis Publishers, 2001.

[14] Helman Cecil, Culture, Health and Illness. London: Butterworth \& Co (Publishers), Ltd, 2007.

[15] Hindriks Jean, Michael Keen, Abhinay Muthoo, Journal of Public Economics 74 (1999) 395-430.

[16] Hofstede Geert, Cultures and Organizations: Software of the Mind. London: McGraw-Hill. 1991.

[17] Ikwenobe Polycarp, Philosophical Perspectives on Communalism and Morality in African Traditions. New York: Lexington Books, 2006.

[18] Klitgaard Robert, International Cooperation Against Corruption Finance \& Development: World Bank, 1998.

[19] Laurent P-J, Semantique Populaire du detournement dans les associations de development en pays mossi (Burkina Faso), in G. Blundo (ed.), monnayer les pouvoirs. Espaces, mecanismes et representations de la corruption, Nouveaux Cashiers de l' IUED, no. 9, Presses Universitaires de France Paris: (2005) 221-48.

[20] Martin Kelly D., Cullen John B., Johnson Jean L., Parboteeah Praveen K., Academy of management 50(6) (2007) 1401-1422.

[21] Mazar, Nina, Aggarwal Pankaj,. Psychological Science 22(7) (2011) 843-848.

[22] Medard F. Jean, Corruption in Neo-Patrimonial States of Sub-Saharan Africa, in A. J. Heidenheimer and M. Johnston (eds), Political Corruption: Concepts and Contexts, Transaction, New Brunswick, 2002, 379-402.

[23] Medard F. Jean, Les paradoxes de la corruption institutionalisee, conference paper, Centre d' Etude d' Afrique Noire, Bordeaux, 2003.

[24] Ministry of Public Service and UBOS, The National Service Delivery Survey Report, Kampala: Ministry of Public Service and UBOS, 2008.

[25] Mishra Ajit, Corruption: A Review. Oxford University Press, 2005.

[26] Mugisha et. al., HIV/AIDS Health Sector review: Health financing building block, Kampala: Ministry of Health, 2010.

[27] Neema Stella, Bukuluki Paul, Identifying the Relationship between HIV and AIDS and Fragility in Local Government Structures in Uganda. IDASA, South Africa, 2010. 
[28] Ottenberg S., Journal of Asian and African Studies 2(1-2) (1967) 26-43.

[29] Peacock James, The Anthropological Lens: Hash Light, Soft Focus. Second Edition. Cambridge: Cambridge University Press, 2001.

[30] Rose-Ackerman Susan, Corruption and Government: Causes, Consequences and Reform. Cambridge UK: Cambridge University Press, 1999.

[31] Shleifer Andrei, Robert Vishny, The Quarterly Journal of Economics 108(3) (1993) 599-617.

[32] Seleim Ahmed, Bontis Nick, Journal of Intellectual Capital 10(1) (2009) 165-184.

[33] Tschudi Finn, Notes towards an optimistic view of restorative justice in international and inter-group conflicts. Paper presented on the Bar Ilan conference on restorative justice and contact hypothesis in managing ethno-national conflicts. Bar Illan University, Tel Aviv, 2006.

[34] Transparency International, Global Corruption Report: Special focus on corruption and health. London: Pluto Press, 2006.

[35] Transparency International, Global Corruption Barometer, (Berlin: TI, 2009), online at: http://www.transparency.org/policy_research/surveys_indices/gcb/2009. Accessed on May 19, 2013.

[36] Transparency International Uganda, Governance, Transparency and Accountability in the Health Sector in Uganda, Kampala: Transparency International Uganda, 2011.

[37] Van der Geest Sjaak, Medical Anthropology Quarterly 15(4) (1984) 87-90.

[38] White A. Leslie, Philosophy of Science 7(4) (1940) 451-463. 